\title{
Longitudinal interrelationship between HIV viral suppression, maternal weight change, breastfeeding, and length in HIV-exposed and uninfected infants participating in the Kabeho study in Kigali, Rwanda
}

\author{
Charlotte Lane, PhD ${ }^{\mathrm{a},}{ }^{*}$, Linda Adair, PhD ${ }^{\mathrm{a}}$, Emily Bobrow, PhD ${ }^{\mathrm{b}}$, Gilles F. Ndayisaba, MD ${ }^{\mathrm{b}}$, \\ Anita Asiimwe, MD ${ }^{\mathrm{b}}$, Placidie Mugwaneza, MD ${ }^{\mathrm{b}}$ \\ a Nutrition Department, University of North Carolina at Chapel Hill, Chapel Hill \\ ${ }^{b}$ Elizabeth Glaser Pediatric AIDS Foundation, Kigali, Rwanda
}

\section{A R T I C L E I N F O}

Article history:

Received 8 December 2019

Accepted 10 August 2020

Available online 15 August 2020

Keywords:

HIV

Breast feeding

Growth

Infant

\begin{abstract}
A B S T R A C T
Purpose: The health of infants that are HIV exposed and uninfected (HEU) is a major public health concern as HIV becomes a chronic condition. We investigate the interrelationship between maternal viral suppression, maternal weight status, breastfeeding, and infants that are HEU.

Methods: The Kabeho study followed 502 HEU infants in Kigali, Rwanda, for 24 months from 2013 to 2014. We use a structural equation modeling approach to investigate the dynamic relationships between viral suppression, maternal weight change, breastfeeding, and infant length for age $z$ score (LAZ) as defined by the WHO.

Results: Older mothers are more likely to be virally suppressed and to breastfeed. Viral suppression and the mother being on antiretroviral treatment for longer were related to lower infant LAZ at three months. A more positive maternal weight change was related to higher infant LAZ at the end of each period. At 12 months, a higher infant LAZ was related to increased probability of continued breastfeeding. At 18 months, continued breastfeeding was related to lower LAZ, and food shortages were related to higher LAZ.

Conclusion: There is a complex interrelationship between viral suppression, maternal weight change, breastfeeding, and infant LAZ. These relationships demonstrate the link between maternal and infant
\end{abstract} health in the context of HIV.
Funding: This work was done in collaboration with the Elizabeth Glaser Pediatric AIDS Foundation, with support from USAID through Cooperative Agreement No. AID-OAA-A-12-00,024.

Conflict of interest and authorship conformation form: Please check the following as appropriate: Yes All authors have participated in (a) conception and design, or analysis and interpretation of the data, (b) drafting the article or revising it critically for important intellectual content, and (c) approval of the final version. Yes This manuscript has not been submitted to, nor is under review at, another journal or other publishing venue. Yes The authors have no affiliation with any organization with a direct or indirect financial interest in the subject matter discussed in the manuscript None The following authors have affiliations with organizations with direct or indirect financial interest in the subject matter discussed in the manuscript.

* Corresponding author. University of North Carolina at Chapel Hill, 123 W. Franklin St, Chapel Hill, NC 27516.

E-mail address: Clane293@live.unc.edu (C. Lane).

\section{Introduction}

Success in the management of HIV has significantly increased the lifespan of women with the disease and reduced vertical transmission, so more infants are born HEU (1). Therefore, the number of infants exposed to but uninfected by HIV is increasing worldwide $(1,2)$. These infants continue to be at increased risk of early morbidity and mortality $(1,3,4)$. Therefore, there is a growing public health focus on the health of infants born to mothers with HIV (1,5).

Linear growth is one aspect of infant health and wellbeing. Growth can be viewed as a determinant of future health or a marker of underlying processes, which also determine future outcomes $(6,7)$. Infant growth is related to school attainment, productivity, cognitive development, wages, obesity, insulin resistance, blood pressure, and more (8). 
Maternal and infant health are inexorably linked, especially through early nutrition and breastfeeding $(9,10)$. This link is particularly important in the context of HIV as the health of the mother and infant are fragile. In this context, maternal and infant health can be connected through several mechanisms, which we explore using a longitudinal, structural equation model (SEM, Fig. 1). Structural equation modeling is similar in theory to tradi tional linear regression. However, in an SEM diagram, the arrows represent a set of hypothetical relationships that can be tested. Instead of specifying and examining one relationship at a time, this approach allows for the simultaneous estimation of multiple re lationships. By doing this, we are able to account for the inherent dependencies between the various factors examined here. The longitudinal, interdependent nature of this analysis is especially important as these factors feedback on one another.

1. We expect that viral suppression will reduce maternal weight loss. HIV progression and ART can induce weight loss through changes in diet, absorption, metabolism, and other factors $(11,12)$. There is conflicting evidence regarding the presence of a relationship between weight loss among lactating women with HIV and disease progression (13-15). However, malnutrition is known to accelerate HIV progression $(16,17)$; therefore, it is possible that weight loss could result in a loss of viral sup pression status. Although there is no association between maternal body mass index (BMI) and disease progression in sub Saharan Africa (18), the effect of changes in weight remains unknown.

2. Similarly, we predict that viral suppression will be related to increased infant length. Maternal viral suppression will decrease infant exposure to HIV through breastmilk (19), thereby decreasing any negative biological effects of HIV exposure on infant growth. Viral suppression will also improve maternal health, decreasing the infant's exposure to other HIV related opportunistic infections, and improving the mother's ability to care for the infant. Measures of maternal viral load and CD4 + are related to infant growth and health outcomes (20-22).

3. We expect that breastfeeding will induce maternal weight loss; however, it is equally possible that women who are rapidly losing weight may choose to stop breastfeeding. It is as yet unclear if HIV increases the energetic demands of breastfeeding; however, breastfeeding requires about 500 kilocalories a day (23). Women may mobilize their fat stores to meet these de mands (23). Or, women with significant weight loss may choose not to breastfeed to preserve their own nutritional resources. The association between breastfeeding and postpartum weight loss remains uncertain (24), with some studies showing no ef fect in women with HIV $(14,15)$. Nonetheless, women in Malawi believe there is an interaction between nutrition, HIV disease progression, and the ability or choice to breastfeed, especially in resource restricted settings (25). This belief is likely to result in women adjusting their breastfeeding status in response to their weight status.

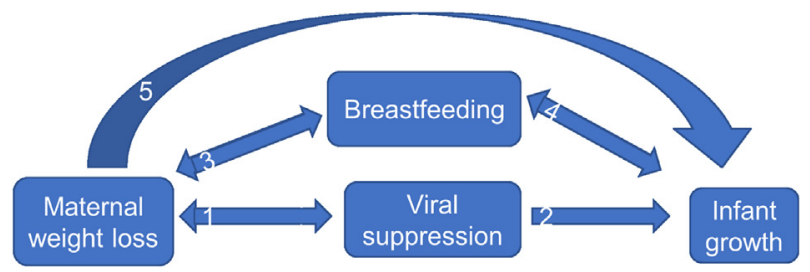

Fig. 1. Theoretical model examining the relationship between maternal nutritional status, viral load, and infant growth.
4. We anticipate that breastfed infants will be longer and, conversely, being longer may be related to the early cessation of breastfeeding. Breastfeeding supports infant growth, and rapidly growing infants may breastfeed more. Many studies have found relationships between breastfeeding and growth outcomes, but these relationships are not consistent, affecting some measures of weight and length and not others at various ages (26-30). A major limitation of these studies is the possi bility of reverse causation. Women tend to adjust their breast feeding status to cues from the infant and perceived infant health (31-34). As such, it is possible that breastfeeding may affect infant growth, and infant growth may affect breastfeeding decisions.

5. Rapid maternal weight loss may be harmful to infant growth independent of breastfeeding. Some maternal weight loss is expected in the first year after pregnancy, with the rate decreasing over time (35-37). However, among women with HIV in sub Saharan Africa, there is little change in BMI from six to 24 months postpartum (18). The effect of maternal weight status on infant growth after birth remains unclear, with some evidence indicating that low maternal weight may affect infant growth, especially in the context of HIV (38-40). Accelerated weight loss could reflect increasing HIV disease severity. Even mild weight loss is associated with an increased risk of death (41). As such, maternal weight loss could represent maternal depletion, increasing disease severity, or environmental hard ships affecting both the mother and the infant.

\section{Materials and methods}

\section{Cohort description}

The Kabeho Study (Kigali Antiretroviral and Breastfeeding Assessment for the Elimination of HIV) enrolled 608 pregnant or postpartum women with HIV participating in the prevention of mother to child HIV transmission programs in selected high volume health facilities in Kigali, Rwanda from April 2013 to January 2014 (Fig. 2). All women were placed on lifelong antire troviral therapy (Option $\mathrm{B}+$ ). The majority of women received tenofovir, lamivudine, and efavirenz. In some cases of contraindi cations, zidovudine replaced tenofovir or nevirapine replaced efa virenz. Women were required to have documented HIV infection, plan to remain in the Kigali area after delivery, and provide consent. HIV testing of the infants was conducted according to standard national procedures for early infant diagnosis by HIV polymerase chain reaction (PCR) or rapid HIV testing at 6 weeks, 9 months, 18 months, and 24 months by the National Reference Laboratory using Roche COBAS AmpliPrep/TaqMan (V2.0).

Study visits were conducted at the health facilities within two weeks of birth; at six, 10 , and 14 weeks; monthly from four to 18 months; and at 21 and 24 months. Attendants in the clinical settings measured birth weight where births took place. If recorded birth weight was not available, we used measurements taken at the Kabeho birth visit as a measure of neonatal weight. At each visit, trained nurses took duplicate measures of infant length to the nearest centimeter $(\mathrm{cm})$ using Shorr boards, and weight to the nearest 10 grams using United Nations International Children's Relief Fund scales. Maternal weight was measured at six, 12, 18, and 24 months. Viral load was measured at birth, 18 months, and 24 months. Viral load testing was conducted using the Roche Cobas Ampli Prep/Cobas TaqMan HIV 1 quantitative test. The lower limit of detection for this test (10 copies/mL) was used to define viral suppression. At each visit, women were asked if they had experi enced a food shortage in the last month, if they were currently 


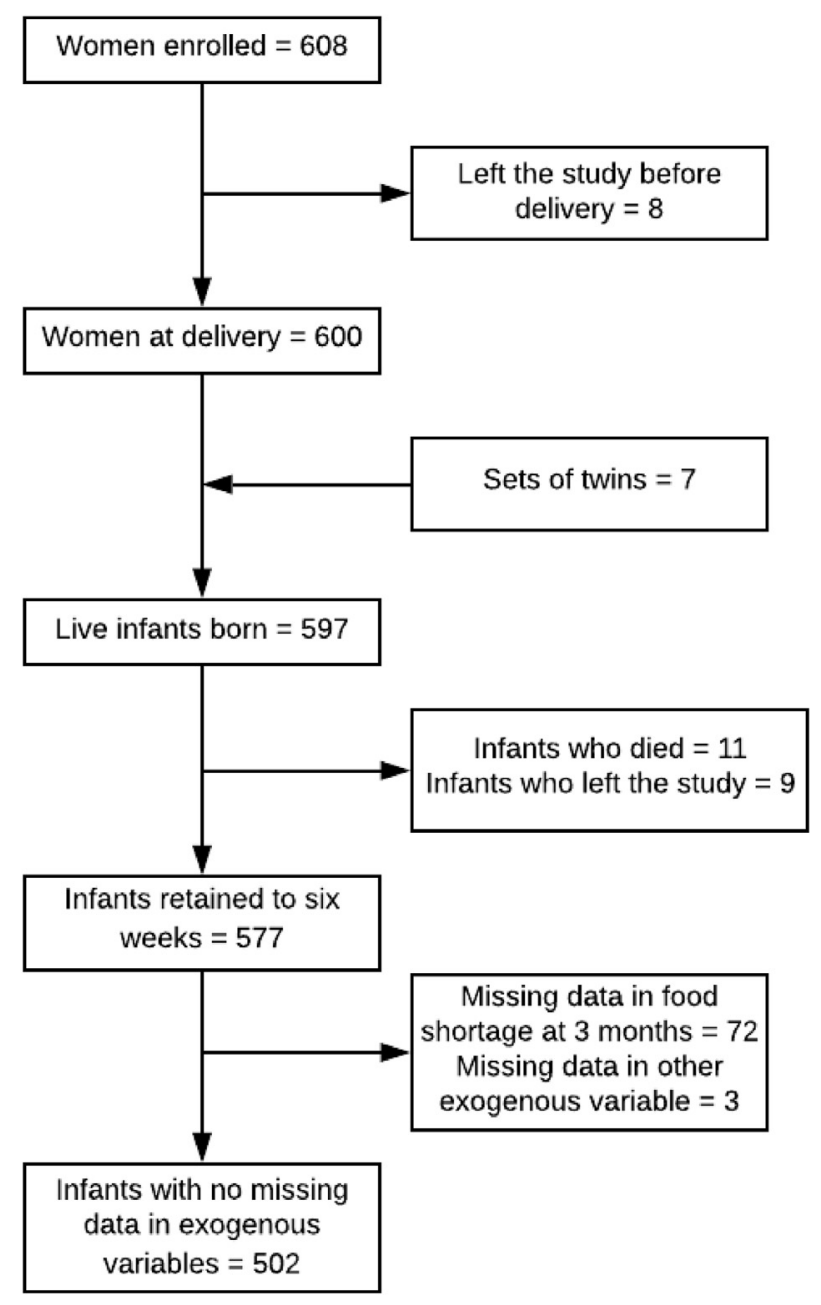

Fig. 2. Flow diagram indicating reflecting how the final analytical sample was arrived at.

breastfeeding, and if their infant had been sick since the last visit. Women were asked if they had a cesarean delivery, a predictor of breastfeeding initiation in Rwanda, and the date at which ART treatment was initiated.

\section{Defining key variables}

Maternal rate of weight change was calculated by subtracting the weight at the beginning of the period from the weight at the end and dividing by the number of months between measures. A factor score was developed for each facility that represented the level of training of staff in infant feeding counseling. This was a significant predictor of breastfeeding initiation in our previous work on the Kabeho sample (unpublished). Because this is a facility level variable, data were clustered at the facility level. Time since the start of antiretroviral therapy (ART) was defined by subtracting the date at which ART was started from the birth date. This results in most values being negative, reflecting starting ART before infant birth. The median time since the initiation of ART was 1.55 years. Infant $\mathrm{z}$ scores were calculated using the WHO igrowup macro parameters (42).

\section{Building the structural equation model}

The SEM was developed in MPLUS using full information maximum likelihood (FIML) (43). Continuous variables, other than
LAZ, were standardized to have a mean of zero and a standard deviation of one. As such, path coefficients can be interpreted similarly to beta coefficients in linear regressions with standardized data.

Temporality was considered in the development of the models. Viral suppression measures can be viewed as reflecting a longer period of suppression, which started several weeks or months before the measure. If this approach is adopted, current viral sup pression could have already affected the current infant length. Alternatively, viral suppression can be viewed as only reflecting current status, and therefore, only affecting future growth out comes. Because 118 women (21\%) initiated treatment within 3 months of birth, we consider the viral birth measure to reflect only the current status and affect only future growth. However, more than $80 \%$ of women showed concordance in their viral status at 18 and 24 months, so these are considered to reflect a chronic state and to have already acted on infant growth by the time of measurement. Maternal weight change is modeled as influencing infant growth by the end of the period. Because breastfeeding re flects a continuous caloric demand, breastfeeding status at the beginning of a period is assumed to affect weight change throughout the period. A reciprocal relationship between breast feeding at the end of a period and weight change throughout the period is modeled as maternal depletion could cause breastfeeding cessation. All values are expected to influence their own subse quent values.

Maternal education, age, and height; time since the initiation of ART; staff trained in infant feeding; delivery method; neonatal WAZ; food shortages; and infant sex are included in the model to control for confounding and allow for model estimation. The model was originally estimated with size outcomes at three, $12,18,21$, and 24 months. However, the 12 and 21 month time points were dropped due to a large amount of missingness, which severely reduced the available sample size. The ratio of children to adults in the household, dietary diversity, meal frequency, and illness epi sodes were included in the original model but removed due to poor model fit. Breastfeeding at 24 months was dropped from the model due to limited variation; $97 \%$ of infants were already weaned.

\section{Results}

A final sample of 502 infants had sufficient data to be included in the analysis (Table 1). Maternal weight change was unrelated to food security or viral suppression status. In univariate analysis, weight change from 6 to 12 and 18-24 months was inversely related to weight at the beginning of the period ( $p$ value $<0.04$ ). Maternal BMI was approximately $23 \mathrm{~kg}$ per $\mathrm{m}^{2}$ at all time periods. Infants whose mothers reported a food shortage were more likely to be breastfed at 18 months ( $p$ value $<0.001$ ).

The final model estimated is illustrated in Figure 3 (Sup 1). The root mean square error of approximation (RMSEA) was 0.01 . The standardized root mean square residual (SRMR) was 0.08 . The comparative fit index (CFI) was 0.97 . These values indicate adequate model fit.

Older mothers are more likely to be virally suppressed ( $\left.\begin{array}{ll}\beta & 0.39\end{array}\right)$ and to breastfeed ( $\left.\begin{array}{ll}\beta & 0.17\end{array}\right)$; although, the effect on breastfeeding diminishes with age $\left(\begin{array}{ll}\beta & 0.32\end{array}\right)$. Viral suppression and the mother being on ART for longer are related to lower infant LAZ at three months ( $\beta_{\text {viral suppression }} \quad 0.16$, $\beta_{\text {time on ART }} \quad 0.11$ ). A more positive maternal weight change is related to higher infant

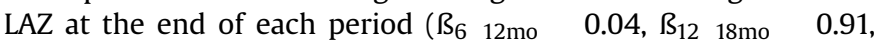
$\beta_{18} 24 \mathrm{mo} \quad 0.11$ ). At 12 months, a higher infant LAZ is related to an increased probability of breastfeeding ( $\beta \quad 0.25$ ). At 18 months,

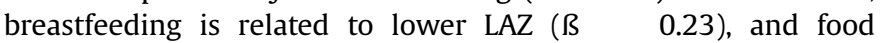


Table 1

Descriptive statistics of sample across time

\begin{tabular}{|c|c|c|c|c|c|c|c|c|c|c|}
\hline & \multicolumn{2}{|l|}{ Baseline } & \multicolumn{2}{|l|}{$12 \mathrm{mo}$} & \multicolumn{2}{|l|}{$18 \mathrm{mo}$} & \multicolumn{2}{|l|}{$21 \mathrm{mo}$} & \multicolumn{2}{|l|}{$24 \mathrm{mo}$} \\
\hline & $n /$ mean & $\% / S D$. & $n /$ mean & $\% / S D$. & $n /$ mean & $\% / S D$. & $n /$ mean & $\% / S D$. & $n /$ mean & $\% / S D$. \\
\hline Total $n^{*}$ & 502 & & 409 & & 431 & & 219 & & 355 & \\
\hline Female infant $n^{*}$ & 289 & $52 \%$ & 215 & $52 \%$ & 224 & $52 \%$ & 120 & $55 \%$ & 185 & $52 \%$ \\
\hline Neonatal WAZ & 0.00 & 1.00 & & & & & & & & \\
\hline Maternal age $(\mathrm{y})$ & 29.52 & 6.03 & & & & & & & & \\
\hline Maternal height $(\mathrm{cm})$ & 157.24 & 6.27 & & & & & & & & \\
\hline Time since ART (months) & -39.54 & 66.40 & & & & & & & & \\
\hline Mother completed primary school & 225 & $45 \%$ & & & & & & & & \\
\hline Cesarean delivery & 96 & $19 \%$ & & & & & & & & \\
\hline Staff trained in feeding counseling factor score & -0.6 & 0.79 & & & & & & & & \\
\hline Virally suppressed ( $<10$ copies $/ \mathrm{mL})$ & 276 & $56 \%$ & & & 306 & $78 \%$ & & & 310 & $80 \%$ \\
\hline $\mathrm{LAZ}^{\ddagger .3}$ & -0.81 & 1.09 & -1.28 & 1.17 & -1.52 & 1.12 & -1.66 & 1.10 & -1.55 & 1.03 \\
\hline $\begin{array}{l}\text { Rate of maternal weight Change over } \\
\text { preceding six mo. }(\mathrm{kg})\end{array}$ & & & 0.02 & 0.89 & 0.00 & 0.96 & & & 0.00 & 0.99 \\
\hline Breasfed $^{5}$ & 474 & $94 \%$ & 277 & $64 \%$ & 84 & $20 \%$ & 18 & $5 \%$ & 14 & $3 \%$ \\
\hline
\end{tabular}

* Number with LAZ measurements.

$\dagger$ Weight-for-age z-score.

$\ddagger$ Length-for-age z-score.

$\S$ Baseline is considered $3 \mathrm{mo}$

shortages are related to higher LAZ ( $\beta \quad 0.12$ ). Generally, values among repeated measures predicted subsequent values.

\section{Discussion}

Model fit indexes demonstrate that our structural equation model fits the data. There is persistence in viral suppression, food shortages, breastfeeding status, and infant LAZ; the values at one period are positively related to the values in the following period. Weight change at 12-18 months is related to the inverse change in the subsequent period, reflecting stable maternal weight. The re lationships of the repeated measures over time are both logical and intuitive, indicating that the model is well specified.

Maternal weight change was related to higher infant LAZ at the end of the period. A standard deviation $(0.9 \mathrm{~kg})$ increase in maternal weight change from six to 12 months was related to a 0.04 unit increase in infant LAZ, holding all other factors constant. However, the pathways between weight change and LAZ function independently of breastfeeding, thus it is unlikely that this rela tionship was the result of maternal depletion leading to the mother being unable to adequately care for her infant. At six and 18 months, 10-13 women had BMIs less than 18 . There was no relationship between viral suppression and weight change; there fore, it is unlikely that weight change represents a measure of disease severity in our sample. Furthermore, because food security and maternal weight change were not related in univariate analysis or in this structural equation model, and maternal education does not affect infant LAZ, maternal weight change is unlikely to be acting as a measure of socioeconomic status. As such, maternal weight change must reflect some other environmental factor that supports infant and maternal wellbeing. Future research should attempt to identify this protective factor.

Older women were more likely to be virally suppressed and to breastfeed. There was little difference in mortality risk between individuals with HIV initiating treatment between the ages of 18-30 and 30-40 in South Africa, indicating little difference in disease progression (44). In the United States and Canada, older individuals were more likely to achieve viral suppression (45). This may be because older individuals have better adherence (46). We were unable to consider adherence because most of our

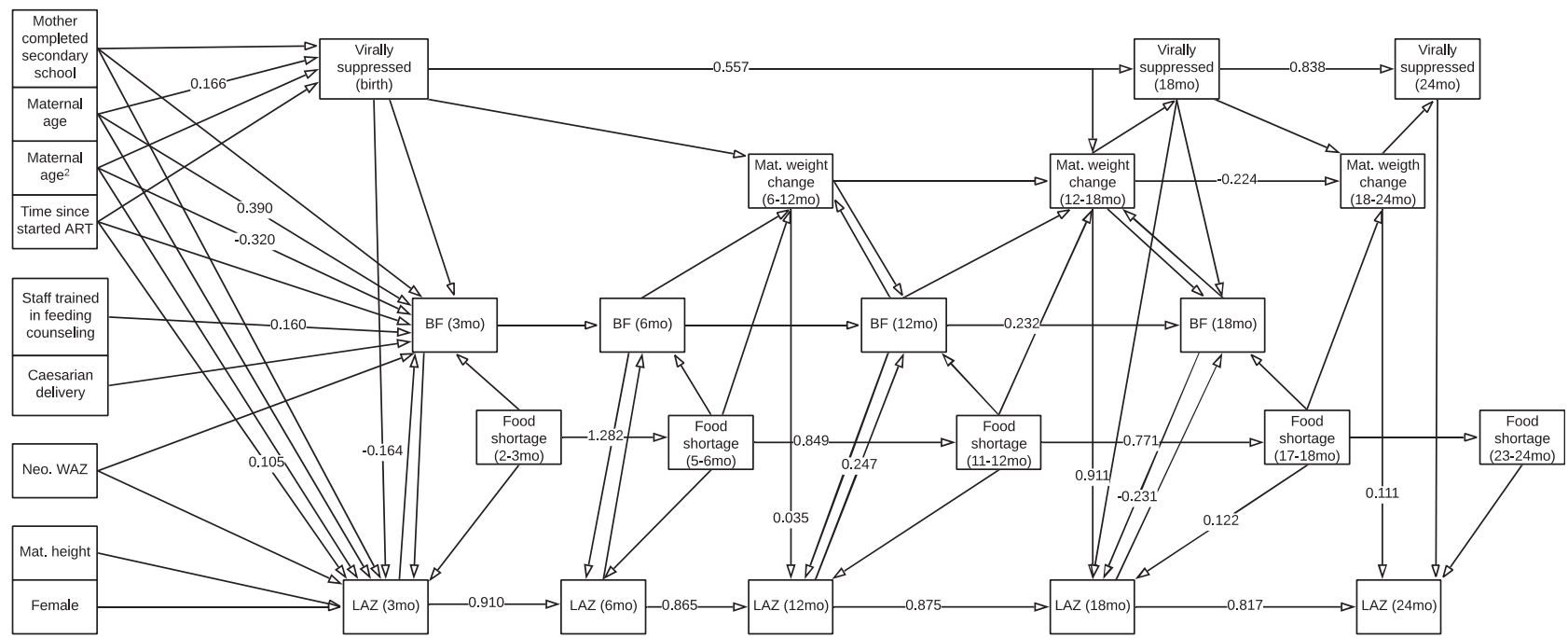

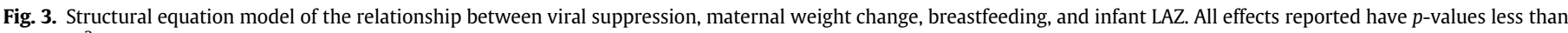
0.05 . Age $^{2}$ reflects and age squared term. 
participants reported perfect adherence. The association be tween maternal age and breastfeeding is well established (47-51).

Women who initiated ART treatment with standard deviation (5.5 years) more recently have infants with 0.11 unit higher LAZ. This pathway functions independently viral suppression, indicating that it does not reflect the HIV disease state. The effect of exposure to ART on infant growth is unknown, but certain drugs have been associated with infant growth in utero $(1,3,52,53)$. While the effects of ART exposure through breastmilk are less clear, the majority of women in this study received reverse transcriptase inhibitors, which are transferred through breastmilk and could have similar effects postnatally (54). Infants whose mothers started treatment more recently may have less exposure to ART and, therefore, better early growth. This could also explain the negative association be tween maternal viral suppression and early LAZ. Women with more medication in their bodies are more likely to be suppressed, their infants are exposed to more of the treatment, and the drug has a larger, negative effect on growth.

The hypothesized negative effect of ART on LAZ is supported by the lack of a relationship between viral suppression and growth at 18 and 24 months when infants were likely to have already been weaned, and therefore, would not be exposed to ART through breastmilk. However, at 18 months, breastfeeding was related to decreased linear growth, possibly because continued exposure to HIV and ART was harmful. Furthermore, infants who were still breastfed at this time may not receive sufficient complementary foods. These infants have lower dietary diversity and meal frequency.

In sub Saharan Africa, breastfed infants ages 12-18 months are shorter and lighter than their weaned counterparts (55). However, this analysis was unable to determine the direction of causation. At 12 months, taller infants were more likely to still be breastfed and, at 18 months, breastfed infants tended to be shorter. This indicates the possibility of a two way, time varying relationship that should be investigated further in future research.

The reason for a positive relationship between food shortages on LAZ at 18 months remains unclear. Although non significant in the model, infants who experienced food shortages at 18 months were more likely to be breastfed than those who do not. The same altered dietary pattern associated with continued breastfeeding was associated with food shortages. Food shortages were also associ ated with lower maternal height and education. Therefore, the relationship between food shortages and LAZ must be considered in the context of the complete model and other sources of variation. In univariate analysis, food shortages at 18 months were related to decreased LAZ ( $\beta \quad 0.41, p$ value 0.003 ); however, in multi variate linear regressions, this relationship became non significantly positive. As such, the relationship between food se curity and LAZ at this age likely reflects an interaction between this variable and the others in the model.

This study has several limitations. First, structural equation modeling is often used as an explicitly causal framework. However, there no need to make causal claims because structural equation modeling is employed. Although we hypothesize about potential mechanisms, our analysis does not demonstrate causation. Second, our sample has some loss to follow up. The use of FIML allows in fants to contribute partial data and only drops infants with missing data in the exogenous variables. The mechanisms reflected in our dataset should function similarly within the subgroup of infants who were lost to follow up. Finally, because we do not have a comparator with infants without HIV exposure, we are unable to determine if the pathways, which are not specific to HIV, such as maternal weight change, would act similarly in a population without HIV exposure.

\section{Conclusions}

We demonstrate the relationship between maternal and infant health in the context of HIV. Time on ART and viral suppression are both related to decreased early infant LAZ. Maternal weight change is correlated with infant LAZ. This supports the ongoing shift in the public health approach to postpartum care that prioritizes the wellbeing of the mother infant dyad rather than considering each separately. Additional work is needed to understand how the mother and infant influence one another, and their health responds to their shared environment.

\section{Acknowledgments}

We acknowledge the contributions of Margaret Bentley, Ste phanie Martin, and Audrey Pettifor in the development of the hy potheses presented here.

\section{References}

[1] Evans C, Jones CE, Prendergast AJ. HIV-exposed Uninfected Infants: New Global Challenges in the Era of Paediatric HIV Elimination. Lancet Infect Dis 2016;16(6):e92 107.

[2] Filteau S. The HIV exposed, uninfected African child. Trop Med Int Health 2009;14(3):276 87.

[3] Desmonde S, Goetghebuer T, Thorne C, Leroy V. Health and survival of HIV perinatally exposed but uninfected children born to HIV-infected mothers. Curr Opin HIV AIDS 2016;11(5):465 76.

[4] Afran L, Garcia Knight M, Nduati E, Urban BC, Heyderman RS, RowlandJones SL. HIV-exposed uninfected children: A growing population with a vulnerable immune system? Clin Exp Immunol 2014;176(1):11 22.

[5] Slogrove A, Becquet R, Chadwick E, Cotet H, Essajee S, Hazra R, et al. Surviving and Thriving Shifting the Public Health Response to HIV-Exposed Uninfected Children: Report of the 3rd HIV-Exposed Uninfected Child Workshop. Front Pediatr 2018;6:1 5 .

[6] Dewey KG, Begum K. Long-term consequences of stunting in early life. Matern Child Nutr 2011;7(Suppl. 3):5 18.

[7] Leroy JL, Frongillo EA. Perspective: What Does Stunting Really Mean? A Critical Review of the Evidence. Adv Nutr 2019:1 9.

[8] Adair LS. Long-term consequences of nutrition and growth in early childhood and possible preventive interventions. Nestle Nutr Inst Workshop Ser 2014;78:111 20.

[9] Dieterich CM, Felice JP, O'Sulliivan E, Rasmussen K. Breastfeeding and Health Outcomes fro the Mother-Infant Dyad. Pediatr Clin North Am 2013;60(1): 3148.

[10] Ramakrishnan U, Grant F, Goldenberg T, Zongrone A, Martorell R. Effect of women's nutrition before and during early pregnancy on maternal and infant outcomes: A systematic review. Paediatr Perinat Epidemiol 2012;26(Suppl. 1): 285301.

[11] Mangili A, Murman DH, Zampini AM, Wanke CA, Mayer KH. Nutrition and HIV Infection: Review of Weight Loss and Wasting in the Era of Highly Active Antiretroviral Therapy from the Nutrition for Healthy Living Cohort. Clin Infect Dis 2006;42(6):836 42.

[12] Kayira D, Bentley ME, Wiener J, Mkhomawanthu C, King CC, Chitsulo P, et al. A lipid-based nutrient supplement mitigates weight loss among HIV-infected women in a factorial randomized trial to prevent mother-to-child transmission during exclusive breastfeeding. Am J Clin Nutr 2012;95:759 65.

[13] Koyanagi A, Humphrey JH, Moulton LH, Ntozini R, Mutasa K, Iliff P, et al. Predictive Value of Weight Loss on Mortality of HIV-Positive Mothers in a Prolonged Breastfeeding Setting. AIDS Res Hum Retroviruses 2011;27(11): 11418.

[14] Somé EN, Engebretsen IMS, Nagot N, Meda NY, Vallo R, Kankasa C, et al. HIV-1 disease progression in immune-competent HIV-1-infected and breastfeeding mothers participating in the ANRS 12174 clinical trial in Burkina Faso, South Africa, Uganda and Zambia: A cohort study. BMJ Open 2018;8(4):1 14.

[15] Somé EN, Engebretsen IMS, Nagot N, Meda NY, Vallo R, Kankasa C, et al. Changes in body mass index and hemoglobin concentration in breastfeeding women living with HIV with a CD4 count over 350: Results from 4 African countries (The ANRS 12174 trial). PLoS One 2017;12(5):1 16.

[16] Anabwani G, Navario P. Nutrition and HIV/AIDS in sub-Saharan Africa: An overview. Nutrition 2005;21(1):96 9.

[17] Duggal S, Chugh TD, Duggal AK. HIV and malnutrition: Effects on immune system. Clin Dev Immunol 2012;2012.

[18] The Kesho Bora Study Group. Maternal HIV-1 Disease Progression 1824 Months Postdelivery According to Antiretroviral Prophylaxis Regimen (TripleAntiretroviral Prophylaxis During Pregnancy and Breastfeeding vs Zidovudine/Single-Dose Nevirapine Prophylaxis): Kesho Bora Random Hiv/ aids. Clin Infect Dis 2012;55. 
[19] Rousseau CM, Nduati RW, Richardson BA, Steele MS, John-stewart GC, Mboringacha DA, et al. Longitudinal Analysis of Human Immunodeficiency Virus Type 1 RNA in Breast Milk and of Its Relationship to Infant Infection and Maternal Disease. J Invest Dermatol 2003;187:741 7.

[20] Morden E, Technau KG, Giddy J, Maxwell N, Keiser O, Davies MA. Growth of HIV-exposed uninfected infants in the first 6 months of life in South Africa: The IeDEA-SA collaboration. PLoS One 2016;11(4):1 15.

[21] Kuhn L, Kasonde P, Sinkala M, Kankasa C, Semrau K, Scott N. Does Severity of HIV Disease in HIV-infected Mothers Affect Mortality and Morbidity among their Uninfected Infants? Clin Infect Dis 2005;41(11):1654 61.

[22] Yeganeh N, Watts DH, Xu J, Kerin T, Joao EC, Pilotto JH, et al. Infectious Morbidity, Mortality and Nutrition in HIV-Exposed, Uninfected, Formula Fed Infants: Results from the HPTN 040/PACTG 1043 Trial. Pediatr Infect Dis J 2018:1.

[23] Kosmiski L. Energy expenditure in HIV infection. Am J Clin Nutr 2011;94(6): $1677 \mathrm{~S} 82 \mathrm{~S}$.

[24] Chowdhury R, Sinha B, Sankar M, Taneja S, Bhandari N, Rollins N, et al Breastfeeding and maternal health outcomes: a systematic review and metaanalysis. Acta Paediatr 2015;104:96 113.

[25] Bentley ME, Corneli AL, Piwoz E, Moses A, Nkhoma J, Tohill BC, et al. Perceptions of the role of maternal nutrition in HIV-positive breasf-feeding women in Malawi. Am Soc Nutr Sci 2005:945 9.

[26] Kindra G, Coutsoudis A, Esposito F, Esterhuizen T. Breastfeeding in HIV exposed infants significantly improves child health: A prospective study. Matern Child Health J 2012;16(3):632 40.

[27] Kuchenbecker J, Jordan I, Reinbott A, Herrmann J, Jeremias T, Kennedy G, et al. Exclusive breastfeeding and its effect on growth of Malawian infants: results from a cross-sectional study. Paediatr Int Child Health 2015;35(1):14 23.

[28] Wright M, Bentley M, Mendez M, Adair L. The interactive association of dietary diversity scores and breast-feeding status with weight and length in Filipino infants aged 6-24 months. Public Health Nutr 2015;18(10):1762 73.

[29] Kamudoni P, Maleta K, Shi Z, Holmboe-Ottesen G. Exclusive breastfeeding duration during the first 6 months of life is positively associated with lengthfor-age among infants 6-12 months old, in Mangochi district, Malawi. Eur J Clin Nutr 2015;69(1):96 101.

[30] Eriksen KG, Johnson W, Sonko B, Prentice AM, Darboe MK, Moore SE. Following the World Health Organization's Recommendation of Exclusive Breastfeeding to 6 Months of Age Does Not Impact the Growth of Rural Gambian Infants. J Nutr 2017;147(2):248 55.

[31] Odom EC, Li R, Scanlon KS, Perrine CG, Grummer-Strawn L. Reasons for Earlier Than Desired Cessation of Breastfeeding. Pediatrics 2013;131(3):e726 32.

[32] Wasser H, Bentley M, Borja J, Davis Goldman B, Thompson A, Slining M, et al. Infants Perceived as "Fussy" Are More Likely to Receive Complementary Foods Before 4 Months. Pediatrics 2011;127(2):229 37.

[33] Matsuyama A, Karama M, Tanaka J, Kaneko S. Perceptions of caregivers about health and nutritional problems and feeding practices of infants: A qualitative study on exclusive breast-feeding in Kwale, Kenya. BMC Public Health 2013;13(1):1 13.

[34] Redsell SA, Atkinson P, Nathan D, Siriwardena AN, Swift JA, Glazebrook C. Parents' beliefs about appropriate infant size, growth and feeding behaviour: implications for the prevention of childhood obesity. BMC Public Health 2010:10:711.

[35] Linné Y, Dye L, Barkeling B, Rossner S. Long-term weight development in women: A 15-year follow-up of the effects of pregnancy. Obes Res 2004;12(7):1166 78.

[36] Haiek LN, Kramer MS, Ciampi a, Tirado R. Postpartum weight loss and infant feeding. J Am Board Fam Pract 2001;14(2):85 94.

[37] Abebe D, Soest T, Holle A, Zerwas S, Torgersein L, Bulik C. Developmental trajectories of postpartum weight 3 years after birth: Norwegian mother and child cohort study. Matern Child Nutr 2015:19(4):917 25.
[38] Wrottesley SV, Lamper C, Pisa PT. Review of the importance of nutrition during the first 1000 days: Maternal nutritional status and its associations with fetal growth and birth, neonatal and infant outcomes among African women. J Dev Orig Health Dis 2015;7(2):144 62.

[39] Wilkinson AL, Pedersen SH, Urassa M, Michael D, Todd J, Kinung'hi S, et al Associations between gestational anthropometry, maternal HIV, and fetal and early infancy growth in a prospective rural/semi-rural Tanzanian cohort 2012-13. BMC Pregnancy Childbirth 2015;15(1):1 13.

[40] Widen EM, Bentley ME, Kayira D, Chasela CS, Jamieson DJ. Tembo M, et al. Maternal Weight Loss during Exclusive Breastfeeding Is Associated with Reduced Weight and Length Gain in Daughters of HIV-Infected Malawian Women. J Nutr 2013;143(7):1168 75.

[41] Wheeler DA, Gibert CL, Launer CA, Muurahainen N, Elion RA, Abrams DI, et al Weight loss as a predictor of survival and disease progression in HIV infection. Terry Beirn Community Programs Clin Res AIDS. J Acquir Immune Defic Syndr Hum Retrovirol 1998;18:80 5.

[42] World Health Organization. WHO Anthro: igrowup. Geneva, Switzerland: Department of nutrition; 2011.

[43] Muthen L, Muthen B. Mplus Users Guide. Seventh Ed. Los Angeles, CA: Muthen \& Muthen; 2011.

[44] Maskew M, Brennan AT, MacPhail AP, Sanne IM, Fox MP. Poorer ART outcomes with increasing age at a large public sector HIV clinic in Johannesburg, South Africa. J Int Assoc Physicians AIDS Care 2012:11(1):57 65.

[45] Yehia BR, Rebeiro P, Althoff KN, Agwu AL, Horberg MA, Samji H, et al. Impact of age on retention in care and viral suppression. J Acquir Immune Defic Syndr 2015;68(4):413 9.

[46] Hinkin CH, Hardy DJ, Mason KI, Castellon SA, Durvasula RS, Lam MN, et al, Medication adherence in HIV-infected adults: Effect of patient age, cognitive status, and substance abuse. Aids 2004;18(Suppl. 1):1 13.

[47] Maonga AR, Mahande MJ, Damian DJ, Msuya SE. Factors Affecting Exclusive Breastfeeding among Women in Muheza District Tanga Northeastern Tanzania: A Mixed Method Community Based Study. Matern Child Health 2016;20(1):77 87.

[48] Somé EN, Engebretsen IMS, Nagot N, Meda N, Lombard C, Vallo R, et al. Breastfeeding patterns and its determinants among mothers living with $\mathrm{Hu}$ man Immuno-deficiency Virus -1 in four African countries participating in the ANRS 12174 trial. Int Breastfeed J 2017:12(1):1 12.

[49] Kimani-Murage EW, Wekesah F, Wanjohi M, Kyobutungi C, Ezeh AC, Musoke RN, et al. Factors affecting actualisation of the WHO breastfeeding recommendations in urban poor settings in Kenya. Matern Child Nut 2015;11(3):314 32

[50] Kok Leong T. Factors associated with exclusive breastfeeding among infants under six months of age in peninsular malaysia. Int Breastfeed J 2011;6(1):2.

51] Narayan S, Natarajan N, Bawa KS. Maternal and neonatal factors adversely affecting breastfeeding in the perinatal period. Med I Armed Forces India 2005;61(3):216 9.

[52] Powis K, Seaton L, Ogqu A, Lockman S, Dryden-Peterson S, van Widenfelt E. Effects of in Utero Antiretroviral Exposure on Longitudinal Growth of HIVexposed Uninfected Infants in Botswana. J Acquir Immune Defic Syndr 2011;56(2):131 8.

[53] Denneman L, Cohen S, Godfried M, van Leeuwen E, Nellen J, Kuijpers T, et al. Exposure to improved nutrition from conception to age two years and adult cardiometabolic disease risk. Lancet Glob Heal 2018;(8):e875 84.

54] Waitt C, Low N, Van de Perre P, Lyons F, Loutfy M, Aebi-Popp K. Does U U for breastfeeding mothers and infants? Breastfeeding by mothers on effective treatment for HIV infection in high-income settings. Lancet HIV 2018;5(9):e531 6.

[55] Caulfield LE, Bentley ME, Ahmed S. Is prolonged breastfeeding associated with malnutrition? Evidence from nineteen demographic and health surveys. Int J Epidemiol 1996;25(4):693 703. 


\section{Appendix}

Supplemental Table 1

Weights of all variables in the structural equation model

\begin{tabular}{|c|c|c|c|c|}
\hline Acted upon variable & Acting variable & Coefficient & SE. & $p$-value \\
\hline \multirow[t]{4}{*}{ Virally suppressed at birth } & Time since the initiation of ART (d) & 0.123 & 0.063 & .051 \\
\hline & Maternal age (y) & 0.166 & 0.066 & .012 \\
\hline & Maternal age $^{2}(\mathrm{y})$ & -0.032 & 0.066 & .628 \\
\hline & Mother attended secondary school (binary) & 0.01 & 0.145 & .942 \\
\hline \multirow[t]{10}{*}{ Breastfeeding at 3 mo. } & Time since the initiation of ART (d) & 0.045 & 0.052 & .385 \\
\hline & Maternal age $(\mathrm{y})$ & 0.39 & 0.071 & 0 \\
\hline & Maternal age $^{2}(\mathrm{y})$ & -0.32 & 0.058 & 0 \\
\hline & Mother attended secondary school (binary) & -0.008 & 0.131 & .949 \\
\hline & Neonatal WAZ & -0.011 & 0.062 & .861 \\
\hline & Food shortage at $3 \mathrm{mo}$. (binary) & 0.07 & 0.082 & .391 \\
\hline & Virally suppressed at birth (binary) & 0.079 & 0.09 & .377 \\
\hline & LAZ at 3 mo. & 0.202 & 0.412 & .624 \\
\hline & Staff trained in infant feeding counseling (continuous factor) & 0.16 & 0.081 & .049 \\
\hline & Planned caesarian delivery (binary) & -0.076 & 0.118 & .523 \\
\hline \multirow{10}{*}{ LAZ at 3 mo. } & Time since the initiation of ART (d) & 0.105 & 0.04 & .009 \\
\hline & Maternal age (y) & 0.119 & 0.16 & .46 \\
\hline & Maternal age $^{2}(\mathrm{y})$ & 0.005 & 0.127 & .966 \\
\hline & Mother attended secondary school (binary) & 0.075 & 0.076 & .322 \\
\hline & Neonatal WAZ & -0.02 & 0.051 & .697 \\
\hline & Food shortage at $3 \mathrm{mo}$. (binary) & -0.091 & 0.097 & .35 \\
\hline & Virally suppressed at birth (binary) & -0.164 & 0.062 & .008 \\
\hline & Maternal height $(\mathrm{cm})$ & -0.032 & 0.05 & .523 \\
\hline & Breastfeeding at $3 \mathrm{mo}$. (binary) & -0.524 & 0.591 & .376 \\
\hline & Female infant (binary) & 0.179 & 0.141 & .203 \\
\hline \multirow[t]{3}{*}{ Breastfeeding at 6 mo. } & Breastfeeding at $3 \mathrm{mo}$. (binary) & 3.674 & 4.356 & .399 \\
\hline & LAZ at 6 mo. & 0.495 & 0.61 & .418 \\
\hline & Food shortage at 6 mo. (binary) & 0.01 & 0.135 & .939 \\
\hline \multirow[t]{3}{*}{ LAZ at 6 mo. } & LAZ at $3 \mathrm{mo}$. & 0.91 & 0.036 & 0 \\
\hline & Breastfeeding at 6 mo. (binary) & -0.046 & 0.052 & .369 \\
\hline & Food shortage at $12 \mathrm{mo}$. (binary) & -0.009 & 0.05 & .861 \\
\hline Food shortage at 6 mo. & Food shortage at $3 \mathrm{mo}$. (binary) & 1.282 & 0.072 & 0 \\
\hline \multirow{4}{*}{ Maternal weight change from 6 to $12 \mathrm{mo}$. } & Virally suppressed at birth (binary) & -0.074 & 0.061 & .226 \\
\hline & Breastfeeding at $6 \mathrm{mo}$. (binary) & 0.06 & 0.12 & .621 \\
\hline & Breastfeeding at $12 \mathrm{mo}$. (binary) & -0.336 & 0.337 & .318 \\
\hline & Food shortage at $6 \mathrm{mo}$. (binary) & 0.098 & 0.081 & .228 \\
\hline \multirow[t]{4}{*}{ Breastfeeding at $12 \mathrm{mo}}$. & Breastfeeding at 6 mo.(binary) & 0.379 & 0.409 & .354 \\
\hline & LAZ at $12 \mathrm{mo}$ & 0.247 & 0.064 & 0 \\
\hline & Food shortage at $12 \mathrm{mo}$. (binary) & 0.11 & 0.065 & .093 \\
\hline & Maternal weight change from 6 to $12 \mathrm{mo} .(\mathrm{kg})$ & 0.316 & 0.274 & .248 \\
\hline \multirow[t]{4}{*}{ LAZ at 12 mo. } & LAZ at 6 mo. & 0.865 & 0.038 & 0 \\
\hline & Breastfeeding at 6 mo.(binary) & 0.002 & 0.036 & .959 \\
\hline & Food shortage at $12 \mathrm{mo}$. (binary) & 0.054 & 0.052 & .3 \\
\hline & Maternal weight change from 6 to $12 \mathrm{mo}$. (kg) & 0.098 & 0.046 & .035 \\
\hline Food shortage at $12 \mathrm{mo}$. & Food shortage at $6 \mathrm{mo}$. (binary) & 0.849 & 0.139 & 0 \\
\hline \multirow[t]{5}{*}{ Maternal weight change from 12 to $18 \mathrm{mo}$. } & Virally suppressed at birth (binary) & -0.125 & 0.132 & .345 \\
\hline & Maternal weight change from 6 to $12 \mathrm{mo}$. (kg) & -0.656 & 0.41 & .11 \\
\hline & Breastfeeding at $12 \mathrm{mo}$. (binary) & 0.484 & 0.277 & .08 \\
\hline & Breastfeeding at $18 \mathrm{mo}$. (binary) & -2.92 & 2.686 & .277 \\
\hline & Food shortage at $12 \mathrm{mo}$. (binary) & 0.189 & 0.168 & .26 \\
\hline \multirow[t]{5}{*}{ Breastfeeding at $18 \mathrm{mo.}$} & Breastfeeding at $12 \mathrm{mo}$. & 0.232 & 0.108 & .031 \\
\hline & LAZ at $18 \mathrm{mo}$ & -0.08 & 0.051 & .112 \\
\hline & Food shortage at $18 \mathrm{mo}$. & 0.031 & 0.056 & .575 \\
\hline & Maternal weight change from 12 to $18 \mathrm{mo}$. & 0.911 & 0.142 & 0 \\
\hline & Virally suppressed at $18 \mathrm{mo}$. & -0.046 & 0.109 & .674 \\
\hline LAZ at $18 \mathrm{mo}$. & LAZ at 12 mo. & 0.875 & 0.028 & 0 \\
\hline & Breastfeeding at $18 \mathrm{mo}$. (binary) & -0.231 & 0.11 & .036 \\
\hline & Food shortage at $18 \mathrm{mo}$. (binary) & 0.122 & 0.043 & .004 \\
\hline & Maternal weight change from 12 to $18 \mathrm{mo} .(\mathrm{kg})$ & -0.052 & 0.045 & .251 \\
\hline & Virally suppressed at $18 \mathrm{mo}$. (binary) & -0.015 & 0.051 & .765 \\
\hline Food shortage at $18 \mathrm{mo}$. & Food shortage at $12 \mathrm{mo}$. (binary) & 0.771 & 0.124 & 0 \\
\hline Virally suppressed at $18 \mathrm{mo}$. & Virally suppressed at birth (binary) & 0.557 & 0.166 & .001 \\
\hline & Maternal weight change from 12 to $18 \mathrm{mo} .(\mathrm{kg})$ & -0.106 & 0.13 & .413 \\
\hline Maternal weight change from 18 to $24 \mathrm{mo}$. & Virally suppressed at $18 \mathrm{mo}$. (binary) & -0.036 & 0.068 & .595 \\
\hline & Maternal weight change from 12 to $18 \mathrm{mo} .(\mathrm{kg})$ & -0.224 & 0.048 & 0 \\
\hline & Food shortage at $18 \mathrm{mo}$. (binary) & 0.015 & 0.04 & .704 \\
\hline LAZ at $24 \mathrm{mo}$. & LAZ at $18 \mathrm{mo}$ & 0.817 & 0.027 & 0 \\
\hline & Food shortage at $18 \mathrm{mo}$. (binary) & 0.039 & 0.131 & .767 \\
\hline & Maternal weight change from 18 to $24 \mathrm{mo} .(\mathrm{kg})$ & 0.111 & 0.034 & .001 \\
\hline & Virally suppressed at $24 \mathrm{mo}$. (binary) & -0.032 & 0.038 & .398 \\
\hline Virally suppressed at $24 \mathrm{mo}$. & Virally suppressed at $24 \mathrm{mo}$. (binary) & 0.838 & 0.114 & 0 \\
\hline & Maternal weight change from 18 to $24 \mathrm{mo} .(\mathrm{kg})$ & -0.111 & 0.088 & .204 \\
\hline Food shortage at $24 \mathrm{mo}$. & Food shortage at $18 \mathrm{mo}$. (binary) & 0.104 & 0.096 & .275 \\
\hline
\end{tabular}

$\mathrm{Age}^{2}$ reflects and age squared term. 